\title{
Complexes of heavy metals with nitrogen containing copolymers - electrochemical and physicomechanical properties
}

\author{
S. Ch. Turmanova* \\ Department of Materials Science, Bourgas Assen Zlatarov University, Y.Yakimov Str. 1, Bourgas 8010, Bulgaria
}

Received 21 May 2007; accepted in revised form 8 July 2007

\begin{abstract}
Absrtact. Metal complexes were synthesized on the basis of the copolymers of radiation grafted poly-4-vinylpyridine onto polyethene and polytetrafluoroethene. The formation of the complexes was carried out in solutions of the following salts: $\mathrm{FeCl}_{3} \cdot 6 \mathrm{H}_{2} \mathrm{O}, \mathrm{CoCl}_{2} \cdot 6 \mathrm{H}_{2} \mathrm{O}, \mathrm{VOSO}_{4} \cdot 5 \mathrm{H}_{2} \mathrm{O}, \mathrm{Na}_{2} \mathrm{MoO}_{4} \cdot 2 \mathrm{H}_{2} \mathrm{O}$ and $\mathrm{Na}_{2} \mathrm{WO}_{4} \cdot 2 \mathrm{H}_{2} \mathrm{O}$. The introduction of metal ions depended on the degree of grafting of 4-vinylpyridine and it was found to be from 0.03 to 14.96 and from 0.11 to 34.48 mg metal ions per $g$ of polymer carrier for polytetrafluoroethene and polyethene, respectively. The influence of the metal ion nature on the electrochemical characteristics of nitrogen-containing copolymers was studied. The specific electric resistance of the polymer metal complexes was found to depend on the nature of the metal ion and its content in the complex.

The metal complexes obtained had lower electric resistance than the initial copolymers. This can be explained with the fact that the chelate agents (salts of metals with variable valence) have free ions and electron mobility which improve the electric conductivity of the materials obtained and have a good prospect in many fields as functional polymer. The tensile characteristics of the polymer complexes of heavy metals were also affected by the nature and contents of the ions introduced.
\end{abstract}

Keywords: mechanical properties, poly(ethene), polytetrafluoro(ethene), metal complexes, electrochemical properties

\section{Introduction}

Recently, the polymer-metal complexes attracted the interest of many researchers due to their valuable electric, mechanical and thermal properties and the possibilities for their use as immobilized catalysts in various processes. The use of polymer carrier allows combining the properties of the matrix with the complex-forming ability of the ligands and reveals new perspectives for the design of new materials with an interesting complex of properties.

Radiation initiated grafting is a wide field of polymer chemistry with numerous potential applications of industrial interest. 4-vinylpyridine (4VP) is a monomer polymerizing under initiation by radiation. The surface modification of polymer materials by radiation grafting of this monomer provides possibilities to prepare grafted polymers. Poly-4vinylpyridine (P4VP) and its copolymers are known for their versatility of the possible applications. The copolymer materials based on P4VP are used as membranes for retention of heavy metals [1-3], carriers for immobilization of biologically active substances [4], preparation of polymer adsorbents [5], polymer metal complexes with catalytically active centers [6-9] etc.

The grafted poly-4-vinylpyridine forms stable complexes with transition metal ions and ions of metals of higher valence. The presence of nitrogen containing functional groups leads to formation of metal complexes when treated with solutions of heavy metal salts. The reactions of co-ordination of

*Corresponding author, e-mail: sturmanova@btu.bg

(c) BME-PT and GTE 
the polymer ligands with metal ion and the formation of new structures have been studied mainly by spectroscopic methods [10-12]. The introduction of a metal in the polymer chain provokes changes in polymer behavior and its surface morphology. The polymer-metal complexes contain polymer ligand which has specific structure where the central metal ions are surrounded by different polymer chains. [13].

In the present work, a modern method was used to obtain nitrogen containing copolymers - radiation grafting - which does not require the presence of initiators, allows carrying out the process in wide temperature interval and at high rates. The latter can be easily controlled by varying the dose rate. Besides, the method of radiation grafting ensures purity of the copolymers obtained.

The metal complexes of the nitrogen containing copolymers synthesized by the method described above were studied in the reaction of cyclohexene oxidation with tert-butylhydroperoxide [14].

The present paper reports for the preparation of the metal complexes of radiation grafted nitrogen containing copolymers. The aim of the paper is to determine the electrochemical and physicochemical properties of the complexes between polyethene or polytetrafluoroethene and grafted poly-4vinylpyridine with salts of $\mathrm{FeCl}_{3} \cdot 6 \mathrm{H}_{2} \mathrm{O}$, $\mathrm{CoCl}_{2} \cdot 6 \mathrm{H}_{2} \mathrm{O}, \mathrm{VOSO}_{4} \cdot 5 \mathrm{H}_{2} \mathrm{O}, \mathrm{Na}_{2} \mathrm{MoO}_{4} \cdot 2 \mathrm{H}_{2} \mathrm{O}$ and $\mathrm{Na}_{2} \mathrm{WO}_{4} \cdot 2 \mathrm{H}_{2} \mathrm{O}$, as well as to discuss their possible use in electronics.

\section{Experimental part}

\subsection{Materials}

Nitrogen containing copolymers with different degrees of grafting of $4 \mathrm{VP}$ onto films $(40 \mu \mathrm{m})$ of low density polyethene (LDPE) 'Ropoten T' trade FV 03-223, commercial product of Lukoil Neftochim Co, Bourgas and polytetrafluoroethene (PTFE) 'Ftoroplast-4P', product of ONPO 'Plastpolymer', Russia and 4-vinylpyridine (4VP) (BASF, Germany). All other reagents used $\mathrm{FeCl}_{3} \cdot 6 \mathrm{H}_{2} \mathrm{O}$, $\mathrm{CoCl}_{2} \cdot 6 \mathrm{H}_{2} \mathrm{O}, \mathrm{VOSO}_{4} \cdot 5 \mathrm{H}_{2} \mathrm{O}, \mathrm{Na}_{2} \mathrm{MoO}_{4} \cdot 2 \mathrm{H}_{2} \mathrm{O}$ and $\mathrm{Na}_{2} \mathrm{WO}_{4} \cdot 2 \mathrm{H}_{2} \mathrm{O}, \mathrm{HNO}_{3}$ (Fluka, Switzerland), were analytical grade.

\subsection{Preparation of graft copolymers}

The poly-4-vinylpyridine copolymers (LDPEgraft-P4VP and PTFE-graft-P4VP) were obtained by radiation graft-copolymerization of 4-vinylpyridine (BASF, Germany) onto polyethene and polytetrafluoroethene films using the direct method of batch irradiation with post-effect. The irradiation was carried out with $\gamma$-rays from ${ }^{60} \mathrm{Co}$ source at dose rate of $3.5 \mathrm{KGy} / \mathrm{h}$ and doses from 1 to $35 \mathrm{KGy}$ [15].

The polymer films were immersed in $240 \mathrm{~cm}^{3}$ of 40 mass\% methanol solution of the corresponding monomer placed in $250 \mathrm{~cm}^{3}$ glass reactor. The grafting copolymerization was carried out in inert medium. The polymerization time was $2 \mathrm{~h}$ after each exposition and polymerization temperature was $288 \mathrm{~K}$. Mohr's salt in concentration 1.5 mass\% vs the methanol-monomer solution was used as inhibitor of the homopolymerization. After irradiation, the films were washed with methanol and extracted with methanol for $24 \mathrm{~h}$ to remove unreacted 4-vinylpyridine and its homopolymer. The copolymers obtained were dried in vacuum at $343 \mathrm{~K}$ until constant mass. The nitrogen containing copolymers used for the formation of complexes were with grafting degrees of $4 \mathrm{VP}$ from 17.1 to 74.5 mass $\%$ for polyethene and from 0.7 to 13.4 mass \% for polytetrafluoroethene, respectively.

\subsection{Synthesis of grafted copolymer-metal complexes}

The preparation of grafted copolymer-metal complexes was carried out by treatment with 0.4 mass $\%$ aqueous solutions of $\mathrm{FeCl}_{3} \cdot 6 \mathrm{H}_{2} \mathrm{O}, \mathrm{CoCl}_{2} \cdot 6 \mathrm{H}_{2} \mathrm{O}$, $\mathrm{VOSO}_{4} \cdot 5 \mathrm{H}_{2} \mathrm{O}, \mathrm{Na}_{2} \mathrm{MoO}_{4} \cdot 2 \mathrm{H}_{2} \mathrm{O}$ and $\mathrm{Na}_{2} \mathrm{WO}_{4} \cdot 2 \mathrm{H}_{2} \mathrm{O}$ for $12 \mathrm{~h}$ at $296 \mathrm{~K}$ under continuous stirring. The complexes of $\mathrm{Mo}^{6+}$ and $\mathrm{W}^{6+}$ were prepared in aqueous-acid solutions with $\mathrm{pH} 2.5$ [16].

The treated copolymer-metal complexes were dried under vacuum at $323 \mathrm{~K}$ to constant mass.

\subsection{Determination of metal ions content in the polymer complexes}

The amount of metal ions bonded to the polymer matrix was determined spectrophotometrically on a UV/VIS Spectrometer UNIGAN 8625 at the wavelengths $\left(\lambda_{\max }[\mathrm{nm}]\right)$. The amount of Mo, Co and $\mathrm{W}$, 
were determined spectrophotometrically by complexation with potassium rhodanide: Mo $-\lambda=$ $460 \mathrm{~nm}, \mathrm{Co}-\lambda=620 \mathrm{~nm}$ and $\mathrm{W}-\lambda=405 \mathrm{~nm}$, respectively. The amount of $\mathrm{Fe}, \mathrm{V}$ and $\mathrm{Cu}$, were determined spectrophotometrically by complexation with sulfosalicylic acid, hydrogen peroxide and ammonia at: $\lambda=470 \mathrm{~nm}, \lambda=450 \mathrm{~nm}$ and $\lambda=570 \mathrm{~nm}$, respectively.

\subsubsection{Determination of the amount of cobalt in the polymer complexes}

To draw a standard curve, a standard solution containing $0.4769 \mathrm{~g} \mathrm{CoSO}_{4} \cdot 7 \mathrm{H}_{2} \mathrm{O}$ in $1000 \mathrm{~cm}^{3} \mathrm{H}_{2} \mathrm{O}$ was prepared. The extinctions of $8-10$ samples with different cobalt concentrations were measured at $\lambda_{\max }=620 \mathrm{~nm}$.

The extraction of $\mathrm{Co}^{2+}$ from the polymer metal complex was carried out as follows: exact amount of the sample was inundated with $10 \mathrm{~cm}^{3} 1 \mathrm{n}_{2} \mathrm{SO}_{4}$ for $24 \mathrm{~h}$. Then, $1 \mathrm{~g} \mathrm{KCNS}$ and $10 \mathrm{~cm}^{3} \mathrm{CH}_{3} \mathrm{COCH}_{3}$ were added to $10 \mathrm{~cm}^{3}$ of the solution studied. The mixture was homogenized and the extinction at $\lambda_{\max }=620 \mathrm{~nm}$ was measured.

\subsubsection{Determination of the amount of iron con- tained in the polymer complexes}

To obtain the standard straight line, a $1 \mathrm{~cm}^{3}$ standard solution containing $0.1 \mathrm{mg} \mathrm{Fe}^{3+}$ was prepared. For this purpose, $0.49 \mathrm{~g} \mathrm{FeCl}_{3} \cdot 6 \mathrm{H}_{2} \mathrm{O}$ was dissolved in $1000 \mathrm{~cm}^{3} \mathrm{H}_{2} \mathrm{O}$. The extinctions of $8-10$ samples containing different amounts of iron were measured at $\lambda_{\max }=470 \mathrm{~nm}$.

The iron was extracted from the polymer complex using $\mathrm{HCl}$. Exactly measured sample was inundated with $10 \mathrm{~cm}^{3}$ aqueous solution of $\mathrm{HCl}$ (1:3), then $5 \mathrm{~cm}^{3} 10$ mass\% solution of sulphosalicyl acid $\mathrm{C}_{7} \mathrm{H}_{6} \mathrm{O}_{6} \mathrm{~S} \cdot 2 \mathrm{H}_{2} \mathrm{O}$ were added, followed by $5 \mathrm{~cm}^{3}$ buffer solution $\left(2 \mathrm{NH}_{3}: 3 \mathrm{H}_{2} \mathrm{O}\right)$ to stop the observed change of solution shade. $\mathrm{Fe}^{3+}$ was determined as iron disalcylate. The solution volume was increased to $50 \mathrm{~cm}^{3}$ by adding distilled water, it was homogenized and the intensity of the coloring at $\lambda_{\max }=$ $470 \mathrm{~nm}$ was measured.

\subsubsection{Determination of the amount of tungsten in the polymer complexes}

The standard straight line was drawn by preparing standard solution containing $0.178 \mathrm{~g} \mathrm{Na}_{2} \mathrm{WO}_{4} \cdot 2 \mathrm{H}_{2} \mathrm{O}$ in $1000 \mathrm{~cm}^{3} \cdot \mathrm{H}_{2} \mathrm{O}$. The extinctions of $8-10$ samples containing different amounts of tungsten were measured at $\lambda_{\max }=405 \mathrm{~nm}$.

Tungsten was extracted from the polymer complex by adding $20 \mathrm{~cm}^{3}$ aqueous solution of $\mathrm{HCl}(1: 1)$. Then, $5 \mathrm{~cm}^{3} \mathrm{SnCl}_{2}, 0.2 \mathrm{~cm}^{3} \mathrm{TiCl}_{3}$ and $5 \mathrm{~cm}^{3}$ 20 mass\% KCNS solutions were added. The solution volume was increased to $50 \mathrm{~cm}^{3}$ by adding distilled water and the extinction at $\lambda_{\max }=405 \mathrm{~nm}$ was measured.

\subsubsection{Determination of the amount of molybdenum in the polymer complexes}

The interaction between the molybdenum salts with rodanide ions in the presence of a reducing agent gives several molybdenum-rodanide complexes, among which $\mathrm{Mo}(\mathrm{CNS})_{5}$ has the most intense color. Therefore, aqueous solution of ammonium paramolybdate $\left(\mathrm{NH}_{4}\right)_{6} \mathrm{Mo}_{7} \mathrm{O}_{24} \cdot 4 \mathrm{H}_{2} \mathrm{O}$ with concentration of $0.184 \mathrm{~g} / \mathrm{l}$ was prepared from which $1-10$ drops were taken and added into $100 \mathrm{~cm}^{3}$ measuring flask. Then $35 \mathrm{~cm}^{3} \mathrm{HCl}$ (1:3), $3 \mathrm{~cm}^{3} 20$ mass\% solution of KCNS, $1 \mathrm{~g} \mathrm{KJ}$ and $1 \mathrm{~cm}^{3}$ freshly prepared 1 mass $\%$ solution of $\mathrm{Na}_{2} \mathrm{~S}_{2} \mathrm{O}_{3}$ were added. The flask was vigorously agitated after adding each solution. The solution volume was increased to the mark by adding $\mathrm{HCl}$ and the extinction was measured after $10 \mathrm{~min}$. Standard straight line was drawn describing the dependence between the extinction and mol concentration in the range 1-10 mg/l. Further, exactly measured sample was placed in $100 \mathrm{~cm}^{3}$ flask and $35 \mathrm{~cm}^{3}$ aqueous solution of $\mathrm{HCl}$ (1:3) were added. The solution was stored for $24 \mathrm{~h}$ to eluate Mo, then it was treated by the method described above. The extinction was measured at $\lambda_{\max }=460 \mathrm{~nm}$.

\subsubsection{Determination of the amount of vanadium in the polymer complexes}

In acidic medium, vanadium interacts with $\mathrm{H}_{2} \mathrm{O}_{2}$ to form yellow-orange complex. The standard solution was prepared as follows: $0.1786 \mathrm{~g} \mathrm{~V}_{2} \mathrm{O}_{5}$ (obtained by heating $\mathrm{NH}_{4} \mathrm{VO}_{3}$ at $500-550^{\circ} \mathrm{C}$ ) was dissolved in small excess of $\mathrm{NaOH}$, then it was neutralized with $\mathrm{H}_{2} \mathrm{SO}_{4}$ and distilled water was added to reach solution volume of $1000 \mathrm{~cm}^{3}$. From this solution, $1-8 \mathrm{~cm}^{3}$ were pipetted into $50 \mathrm{~cm}^{3}$ measuring flask and $40 \mathrm{~cm}^{3}$ solution of $1 \mathrm{n}_{2} \mathrm{SO}_{4}$ 
and $1 \mathrm{~cm}^{3} 3$ mass \% solution of $\mathrm{H}_{2} \mathrm{O}_{2}$. They were filled up to the mark with distilled water and, after 10-15 min, the extinction was measured by UV/VIS Spectrometer UNIGAN 8625 at wavelength $\lambda_{\max }=450 \mathrm{~nm}$. Standard straight line describing the dependence between the extinction and vanadium concentration was drawn.

After the extraction of vanadium from the polymer complex with $40 \mathrm{~cm}^{3} 1 \mathrm{n}_{2} \mathrm{SO}_{4}$ for $24 \mathrm{~h}$, vanadium concentration was determined by the method described above. The extinction was measured at $\lambda_{\max }=450 \mathrm{~nm}$.

\subsection{Analyses of the metal complexes of the radiation grafted copolymers}

\subsubsection{Specific electric resistance}

The specific electric resistance $(R[\mathrm{ohm} \cdot \mathrm{m}])$ was determined by the mercury contact method [17]. The complexes fixed between the two compartments of a laboratory cell filled with mercury. The contact area of samples with mercury was $10^{-4} \cdot \mathrm{m}^{2}$. Platinum electrodes were connected to a conductometer (OK-102/1, Hungary) The specific electric resistance $(R)$ was calculated as the reciprocal value of the electric conductivity $(\gamma)$ (Equations (1) and (2)):

$R=\frac{1}{\gamma}[\Omega \cdot \mathrm{m}]$

$\gamma=\frac{\chi d}{F} \cdot 10^{4}[\mathrm{~S} / \mathrm{m}]$

where $\gamma$ - specific electric conductivity $[\mathrm{S} / \mathrm{m}]$; $\chi$ - measured electric conductivity $[\mathrm{S}] ; d$ - thickness of the metal complexes of the radiation grafted copolymers $[\mathrm{m}]$.

\subsubsection{Tensile properties}

The tensile strength $(\sigma[\mathrm{MPa}])$ and elongation $(\varepsilon$ [\%]) of wet film samples and metal complexes were determined according to ASTM D882 on an 'Instron' 4203 instrument at temperature of $293 \mathrm{~K}$ and velocity of $100 \mathrm{~mm} / \mathrm{min}$ (for PTFE) and $50 \mathrm{~mm} / \mathrm{min}$ (for LDPE).

\subsubsection{Thermal analysis}

The thermal properties of the polymers and their metal complexes were determined on an OD-102 derivatograph type, system F. Paulik-J. PaulikL. Erdey (MOM, Budapest, Hungary) by TG curves and following conditions: rate of heating $6 \mathrm{~K} / \mathrm{min}$, temperature range $293-873 \mathrm{~K}$, amount of samples $100 \pm 0.5 \mathrm{mg}$ in air medium.

\section{Results and discussion}

Radiation initiated graft polymerization is of scientific interest in polymer chemistry due to the possibilities it offers for practical implementation of the materials obtained.

By direct irradiation from ${ }^{60} \mathrm{Co} \gamma$-source, copolymers based on LDPE-graft-P4VP and PTFE-graft$\mathrm{P} 4 \mathrm{VP}$ were synthesized with degrees of $4 \mathrm{VP}$ grafting from 17.1 to $74.5 \%$ and from 0.7 to $13.4 \%$, respectively. Methanol solution of the monomer with concentration 40 mass $\%$ was used. The basic characteristics of the copolymers synthesized as ion-exchange membranes were reported in previous papers [15].

An interaction was carried out between part of the copolymers synthesized and aqueous solutions of $\mathrm{FeCl}_{3} \cdot 6 \mathrm{H}_{2} \mathrm{O}, \quad \mathrm{CoCl}_{2} \cdot 6 \mathrm{H}_{2} \mathrm{O}, \quad \mathrm{VOSO}_{4} \cdot 5 \mathrm{H}_{2} \mathrm{O}$, $\mathrm{Na}_{2} \mathrm{MoO}_{4} \cdot 2 \mathrm{H}_{2} \mathrm{O}$ and $\mathrm{Na}_{2} \mathrm{WO}_{4} \cdot 2 \mathrm{H}_{2} \mathrm{O}$ to obtain metal pyridine complexes.

Poly-4-vinylpyridine, when grafted onto LDPE and PTFE films, acts as a chelate center for some ions of transition metals $\left(\mathrm{Fe}^{3+}\right.$ and $\left.\mathrm{Co}^{2+}\right)$ and high valency ions $\left(\mathrm{VO}^{2+}, \mathrm{MoO}_{2}{ }^{2+}\right.$ and $\left.\mathrm{WO}_{2}{ }^{2+}\right)$.

The mechanism of the formation of the "polymer ions' by the reaction of molybdenyl, vanadyl and tungstenyl ones with -O- atoms was studied and described in our earlier paper [16].

The solution of $\mathrm{Na}_{2} \mathrm{MoO}_{4} \cdot 2 \mathrm{H}_{2} \mathrm{O}$ in aqueous solution gives molybdenyl Mo (VI) anions according to the following reaction:

$$
\mathrm{Na}_{2} \mathrm{MoO}_{4} \rightleftarrows 2 \mathrm{Na}^{+}+\mathrm{MoO}_{4}^{2-}
$$

By acidic hydrolysis of the molybdenyl ions, "polymer' anions formed following the reactions :

$7 \mathrm{MoO}_{4}{ }^{2-}+8 \mathrm{H}^{+} \rightleftarrows \mathrm{Mo}_{7} \mathrm{O}_{24}{ }^{6-}+4 \mathrm{H}_{2} \mathrm{O}$

$8 \mathrm{MoO}_{4}{ }^{2-}+12 \mathrm{H}^{+} \rightleftarrows \mathrm{Mo}_{8} \mathrm{O}_{26}{ }^{4-}+6 \mathrm{H}_{2} \mathrm{O}$

In acidic solutions, the 'polymer anions' depolymerize to form molybdenyl cation $\mathrm{MoO}_{2}{ }^{2+}$ along the reaction: 
$\mathrm{Mo}_{7} \mathrm{O}_{24}{ }^{6-}+20 \mathrm{H}^{+} \rightleftarrows 7 \mathrm{MoO}_{2}{ }^{2+}+10 \mathrm{H}_{2} \mathrm{O}$

$\mathrm{Mo}_{8} \mathrm{O}_{26}{ }^{4-}+20 \mathrm{H}^{+} \rightleftarrows 8 \mathrm{MoO}^{2+}+10 \mathrm{H}_{2} \mathrm{O}$

The solution of $\mathrm{Na}_{2} \mathrm{WO}_{4} \cdot 2 \mathrm{H}_{2} \mathrm{O}$ in acidic aqueous solutions lead to formation of tungstenate cations $\left(\mathrm{WO}_{2}^{2+}\right)$ according to similar reactions.

It is well known that vanadium ions form complex compounds with donor atoms like nitrogen, oxygen or sulfur. In aqueous solutions of vanadylsulfate, vanadium exists in the form of vanadyl $\left(\mathrm{VO}^{2+}\right)$ cation [18].

$\mathrm{VOSO}_{4} \rightarrow \mathrm{VO}^{2+}+\mathrm{SO}_{4}^{2-}$

In most cases, the co-ordination number of vanadium is five or six. Many complex compounds containing $\mathrm{VO}^{2+}$ are blue or purple colored and most often, the bidentate ligands form complexes in ratio 2:1 with $\mathrm{VO}^{2+}$.

The metal complexes are formed by bonding the polymer ligands with the metal ions through a reaction between the copolymer containing donor atoms (in this case, $\mathrm{N}-$ atoms) and the metal ions $\left(\mathrm{Fe}^{3+}, \mathrm{Co}^{2+}, \mathrm{VO}^{2+}, \mathrm{MoO}_{2}^{2+}\right.$ and $\left.\mathrm{WO}_{2}^{2+}\right)$. Based on our previous studies [14] and literary data [10, 19], the probable co-ordination structure of the compounds obtained is shown in Figures 1 and 2.

The amount of $\mathrm{Fe}^{3+}, \mathrm{Co}^{2+}, \mathrm{VO}^{2+}, \mathrm{MoO}_{2}{ }^{2+}$ and $\mathrm{WO}_{2}{ }^{2+}$ in the polymer complexes was determined spectrophotometrically and the results are presented in Table 1. As can be seen, the vanadyl ions showed the highest affinity to co-ordination: 34.48 and $14.96 \mathrm{mg}$ metal/g polymer carrier for LDPEgraft-P4VP $(P=74.5 \%)$ and PTFE-graft-P4VP $(P=13.4 \%)$, respectively. The amount of the metal

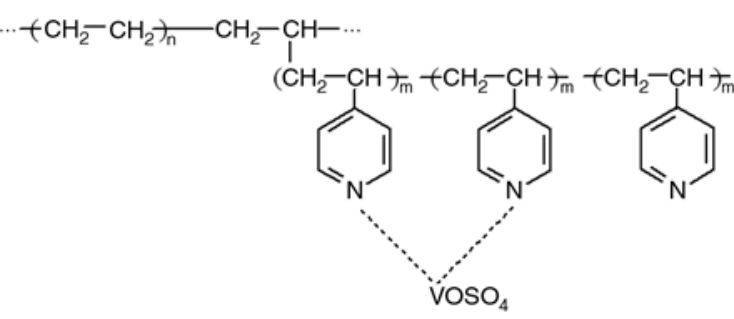

Figure 1. 1-Intramolecular co-ordination structure of PE-graft-P4VP-VO ${ }^{2+}$

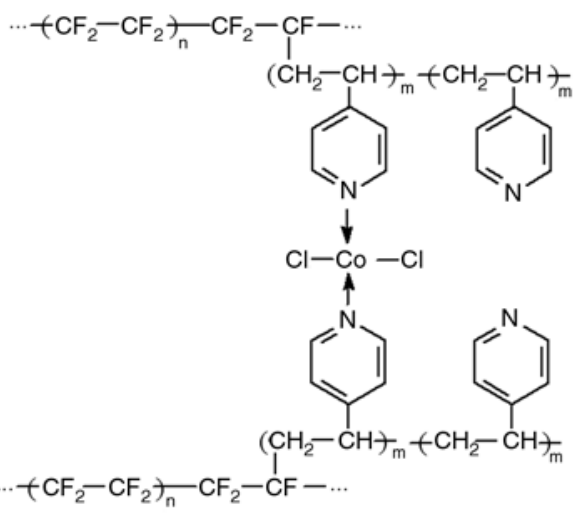

Figure 2. 2-Intermolecular co-ordination structure of PTFE- graft-P4VP-Co ${ }^{2+}$

ions bonded to the nitrogen ligand increased with the increase of the grafting degree. The co-ordination structure of the metal complexes was analyzed using IR, Moessbauer spectroscopy and EPR in our earlier paper [14].

The content of hydrophilic groups in the grafted polymer-metal complexes stipulates their swelling in electrolytes and has strong effect on their specific electric conductivity. Figure 3 . shows the semi-logarithmic dependence of the specific electric resistance $(R[\mathrm{ohm} \cdot \mathrm{m}])$ of some of the materials obtained on the degree of grafting $(P)$ of $4 \mathrm{VP}$.

Table1. Content of metal ions in PE-graft-P4VP and PTFE-graft-P4VP [mg metal/g] polymer carrier

\begin{tabular}{|c|c|c|c|c|c|}
\hline $\begin{array}{c}\text { Polymer carrier } \\
\text { Degree of grafting } \\
\text { P [\%] }\end{array}$ & $\mathrm{Co}^{2+}$ & $\mathrm{Fe}^{3+}$ & $\mathrm{MoO}_{2}^{2+}$ & $\mathrm{VO}^{2+}$ & $\mathrm{WO}_{2}^{2+}$ \\
\hline \multicolumn{6}{|c|}{ PE-graft-P4VP } \\
\hline 17.1 & 0.21 & 2.45 & 3.09 & 18.12 & 0.11 \\
\hline 35.1 & 0.44 & 3.13 & 4.11 & 23.89 & 0.49 \\
\hline 39.2 & 0.51 & 3.98 & 4.39 & 26.77 & 0.54 \\
\hline 66.2 & 0.67 & 4.56 & 4.87 & 29.98 & 0.78 \\
\hline 69.0 & 0.78 & 4.88 & 4.98 & 32.15 & 0.86 \\
\hline 74.5 & 0.93 & 5.30 & 5.15 & 34.48 & 1.03 \\
\hline \multicolumn{6}{|c|}{ PTFE-graft-P4VP } \\
\hline 0.7 & 0.08 & 0.03 & 0.11 & 0.98 & 0.02 \\
\hline 6.5 & 0.56 & 0.14 & 1.56 & 1.87 & 0.12 \\
\hline 8.2 & 0.87 & 0.45 & 5.67 & 5.98 & 0.25 \\
\hline 13.4 & 1.45 & 0.72 & 10.93 & 14.96 & 0.53 \\
\hline
\end{tabular}




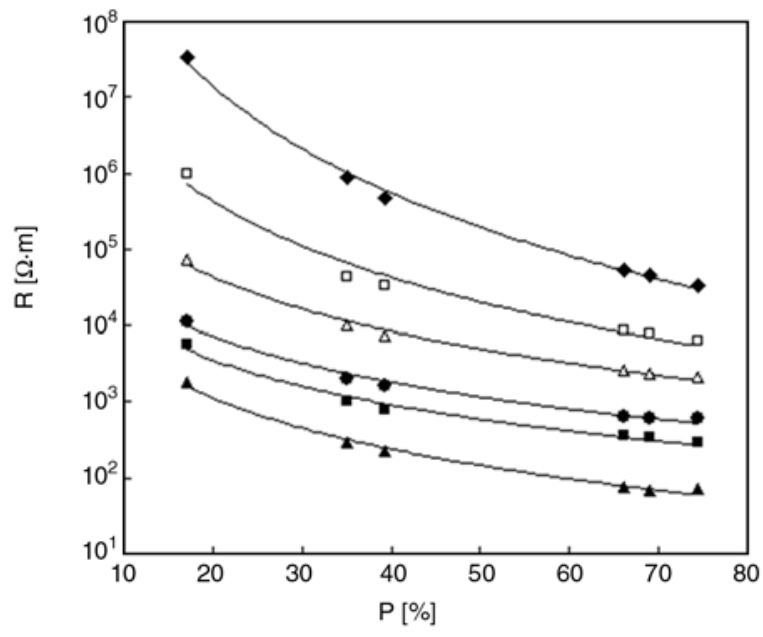

Figure 3. Dependence of the specific electric resistance $(R[\Omega \cdot \mathrm{m}])$ of PE-graft-P4VP films $(\bullet)$ and their metal complexes with $\mathrm{Co}^{2+}(\square), \mathrm{WO}_{2}^{2+}(\Delta)$, $\mathrm{MoO}_{2}^{2+}(\bullet), \mathrm{Fe}^{3+}(\boldsymbol{\bullet})$ and $\mathrm{VO}^{2+}(\boldsymbol{\Delta})$ on the degree of grafting of $4 \mathrm{VP}(P[\%])$

The change of the values of the specific electric resistance of the different complexes can be explained also with the affinity of each metal ion to formation of complexes. The metal ion changes the number of hydrophilic groups in the film and, as a result, affects materials resistance. The influences of the metal ion nature and degree of oxidation to $R$ can be described as follows: LDPE-graft-P4VP > LDPE-graft-P4VP-Co ${ }^{2+}>$ LDPE- raft-P4VP$\mathrm{WO}_{2}{ }^{2+}>$ LDPE- raft-P4VP-MoO ${ }_{2}^{2+}>$ LDPEgraft-P4VP-Fe ${ }^{3+}>$ LDPE- raft-P4VP-VO ${ }^{2+}$.

It can be seen from the figure that, at a grafting degree of $45 \%, R$ of the metal complexes of $\mathrm{Fe}^{3+}$, $\mathrm{Co}^{2+}, \mathrm{MoO}_{2}^{2+}, \mathrm{WO}_{2}^{2+}$ and $\mathrm{VO}^{2+}$, changed within the interval $10^{2}-10^{4} \Omega \cdot \mathrm{m}$, depending on ion nature. Probably, ion associates formed at higher degrees of grafting, which are responsible for the electrochemical properties of the materials. The values of $R$ of LDPE-graft-P4VP changed from $10^{8}$ to $10^{5}$ for degrees of grafting of $4 \mathrm{VP}$ from 17.1 to $74.5 \%$. The higher electric conductivity observed (up to several orders) for the metal complexes compared to the initial copolymers were stipulated by the number and the distribution of the easier ionizing groups in the complexes. The highest electric conductivity showed the metal complexes of the copolymers with $\mathrm{VO}^{2+}$. The materials obtained had lower electric resistance than that of the initial unmodified copolymers. These results can be explained with the fact that the chelating agents (salts of metals of variable valence) have free ions and electron mobility which improve their electric conductivity. Similar investigation on the specific electric resistance of metal complexes based on poly-4vinylpyridine grafted onto polytetrafluoroethene films were also carried out. For polytetrafluoroethene, which is an excellent dielectric, the values of the specific electric resistance changed from $10^{8}$ for the initial copolymer PTFE-graft-P4VP to $10^{3} \Omega \cdot \mathrm{m}$ for the metal complexes with transition metals and the metals with variable valence (Table 2).

The data from DTA analyses of the grafted copolymers of PE with degree of P4VP grafting 74.5\%, PTFE with degree of P4VP grafting $8.1 \%$ and their metal complexes showed that the thermooxidative destruction occurs in two stages: primary thermooxidative destruction of the side chains of grafted P4VP followed by destruction of PE or PTFE polymer matrix. The complexes of all samples did not form a separate phase which would have its own stage of decomposition and, therefore, had similar melting temperatures. The starting decomposion temperature of PE and PTFE metal complexes with $\mathrm{W}$ and $\mathrm{V}$ was by $15-20 \mathrm{~K}$ higher than that of the initial copolymers with the same degree of P4VP grafting - Table 3. It could be suggested that 'cross-linking' takes place between the metal ions and the polymer carrier. For the complexes of PE-graft-P4VP with W and Mo, the first exothermal peak of destruction was shifted to higher temperatures $(545-558 \mathrm{~K})$, than that of the initial PE-graft-P4VP (520 K). This exothermal peak is due to the primary oxidation of $\mathrm{PE}$, where hydroperoxides are accumulated without weight loss. Therefore, the complexes had the necessary

Table 2. Dependence of the specific electric resistance of PTFE-graft-P4VP films and their metal complexes on the degree of grafting of $4 \mathrm{VP}$

\begin{tabular}{|c|c|c|c|c|c|c|}
\hline \multirow{2}{*}{$\begin{array}{c}\text { Degree of } \\
\text { grafting } \\
{[\%]}\end{array}$} & \multicolumn{6}{|c|}{ Specific electric resistance $[\Omega \cdot m]$} \\
\hline & $\begin{array}{l}\text { PTFE-graft- } \\
\text { P4VP }\end{array}$ & $\begin{array}{l}\text { PTFE-graft- } \\
\text { P4VP-Co }{ }^{2+}\end{array}$ & $\begin{array}{l}\text { PTFE-graft- } \\
\text { P4VP-Fe }\end{array}$ & $\begin{array}{l}\text { PTFE-graft- } \\
\text { P4VP-VO }^{2+}\end{array}$ & $\begin{array}{l}\text { PTFE-graft- } \\
\text { P4VP-MoO }{ }_{2}^{2+}\end{array}$ & $\begin{array}{l}\text { PTFE-graft- } \\
\text { P4VP-WO }_{2}{ }^{2+}\end{array}$ \\
\hline 6.5 & $>1.0 \cdot 10^{10}$ & $>1.0 \cdot 10^{8}$ & $1.4 \cdot 10^{7}$ & $4.4 \cdot 10^{5}$ & $2.6 \cdot 10^{6}$ & $7.3 \cdot 10^{6}$ \\
\hline 8.2 & $5.0 \cdot 10^{9}$ & $5.0 \cdot 10^{6}$ & $1.5 \cdot 10^{5}$ & $8.1 \cdot 10^{3}$ & $5.3 \cdot 10^{4}$ & $5.0 \cdot 10^{4}$ \\
\hline 13.4 & $1.3 \cdot 10^{7}$ & $1.3 \cdot 10^{5}$ & $1.3 \cdot 10^{5}$ & $6.1 \cdot 10^{3}$ & $4.1 \cdot 10^{4}$ & $2.2 \cdot 10^{4}$ \\
\hline
\end{tabular}


Table 3. Thermal properties of PE-graft-P4VP and PTFE-graft-P4VP copolymers and their metal complexes with grafting degree $74.5 \%$ and $8.1 \%$

\begin{tabular}{|c|c|c|c|c|}
\hline Metal complex & $\begin{array}{c}\mathbf{T}_{\mathbf{m}} \\
{[\mathbf{K}]}\end{array}$ & $\begin{array}{l}\text { Primary oxidation destruction } \\
\qquad \Delta \mathbf{T}[\mathbf{K}]\end{array}$ & $\begin{array}{l}\text { Main chain destruction } \\
\qquad \Delta \mathrm{T}[\mathrm{K}]\end{array}$ & $\begin{array}{c}\mathbf{T}_{\text {first exothermal peak }} \\
{[\mathrm{K}]}\end{array}$ \\
\hline PE-graft-P4VP & 381 & $494-684$ & $684-771$ & 520 \\
\hline PE-graft-P4VP-VO ${ }^{2+}$ & 383 & $509-687$ & $687-773$ & 527 \\
\hline $\mathrm{PE}$-graft-P4VP-WO ${ }_{2}^{2+}$ & 390 & $514-689$ & $689-775$ & 545 \\
\hline PE-graft-P4VP-MoO ${ }^{2+}$ & 393 & $504-693$ & $693-775$ & 558 \\
\hline PE-graft-P4VP-Fe ${ }^{3+}$ & 390 & $505-691$ & $691-772$ & 527 \\
\hline PE-graft-P4VP-Co ${ }^{2+}$ & 385 & $498-688$ & $688-770$ & 539 \\
\hline PTFE-graft-P4VP & 604 & $522-634$ & $634-853$ & - \\
\hline $\mathrm{PTFE}_{\text {-graft-P4VP-VO }}^{2+}$ & 610 & $537-652$ & $652-868$ & - \\
\hline PTFE-graft-P4VP-WO${ }_{2}^{2+}$ & 615 & $549-660$ & $660-872$ & - \\
\hline PTFE-graft-P4VP-MoO ${ }_{2}^{2+}$ & 612 & $530-662$ & $662-870$ & - \\
\hline PTFE-graft-P4VP-Fe ${ }^{3+}$ & 610 & $526-654$ & $654-865$ & - \\
\hline PTFE-graft-P4VP-Co ${ }^{2+}$ & 608 & $587-658$ & $658-867$ & - \\
\hline
\end{tabular}

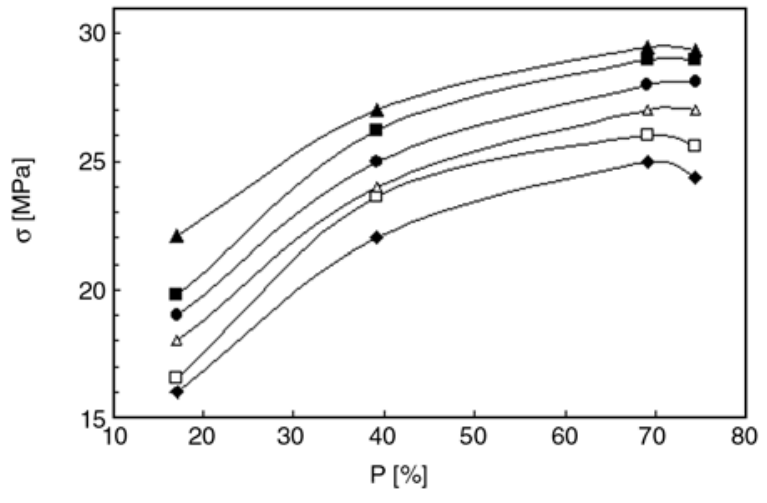

Figure 4. Dependence of the tensile strength $(\sigma[\mathrm{MPa}])$ of LDPE-graft-P4VP films $(\bullet)$ and their metal complexes with $\mathrm{Co}^{2+}(\square), \mathrm{WO}_{2}^{2+}(\Delta)$, $\mathrm{MoO}_{2}{ }^{2+}(\bullet), \mathrm{Fe}^{3+}(\bullet)$ and $\mathrm{VO}^{2+}(\boldsymbol{\Delta})$ on the degree of grafting of $4 \mathrm{VP}(P[\%])$

thermal stability and could be used as catalysts in reactions carried out in the temperature interval 293-383 K and 293-526 K (for metal complexes based on of PE and PTFE, respectively).

The physicomechanical properties of LDPE-graftP4VP and PTFE-graft-P4VP copolymers and their complexes with heavy metals are illustrated in Figures 4-7, respectively.

The metal complexes of LDPE-graft-P4VP showed clearly a tendency to increase of $\sigma$ from 25 to $29 \mathrm{MPa}$ at grafting degrees $P=60 \%$. This increase was probably due to the formation of intermolecular associates (clusters) and additional 'cross-linking' of polymer molecules by the metal ions. At grafting degrees higher than 69\% (higher content of metal ions, respectively), the mechanical strength slightly decreased. This observation can be explained with the simultaneous effects of the following factors: heterogeneity of the process of

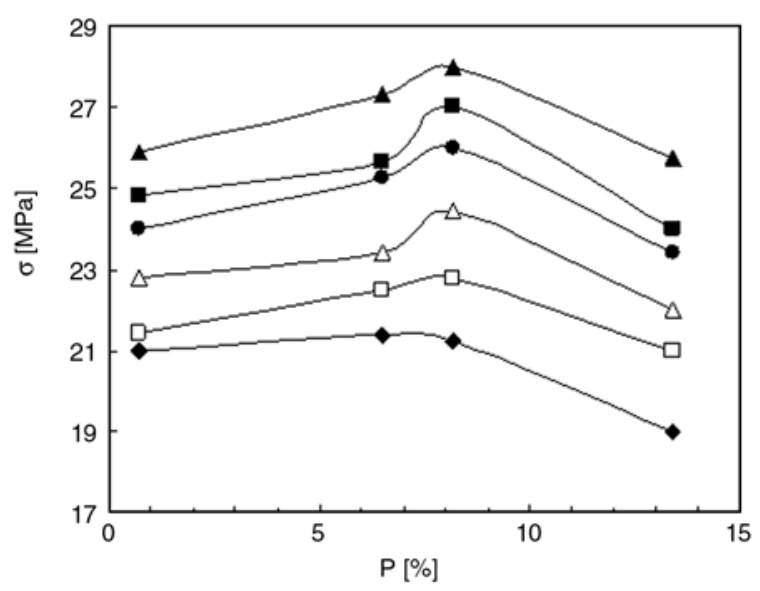

Figure 5. Dependence of the tensile strength $(\sigma[\mathrm{MPa}])$ of PTFE-graft-P4VP films $(\diamond)$ and their metal complexes with $\mathrm{Co}^{2+}(\square), \mathrm{WO}_{2}^{2+}(\Delta)$, $\mathrm{MoO}_{2}^{2+}(\bullet), \mathrm{Fe}^{3+}(\boldsymbol{\bullet})$ and $\mathrm{VO}^{2+}(\boldsymbol{\bullet})$ on the degree of grafting of $4 \mathrm{VP}(P[\%])$

grafting, generation of stresses within the polymer matrix and decrease of the grafted layer thickness. Besides, the tensile strength of the grafted copolymers and their metal complexes measured at $P=69.0 \%$ changed in the following order: LDPEgraft-P4VP $<$ LDPE- raft-P4VP-Co ${ }^{2+}<$ LDPEgraft-P4VP- $\mathrm{WO}_{2}{ }^{2+}<$ LDPE- raft-P4VP- $\mathrm{MoO}_{2}{ }^{2+}$ $<$ LDPE-graft-P4VP-Fe ${ }^{3+}<$ LDPE-graft-P4VP$\mathrm{VO}^{2+}$. These results correlate well with the stability of the chelate complexes.

The metal complexes of PTFE-graft-P4VP showed increased strength at increased content of bonded metal (degree of grafting, respectively). Processes of radiation destruction were observed in this polymer because of the high irradiation doses, which worsened its mechanical properties. The nature of the metal ion involved exerted effect on the 


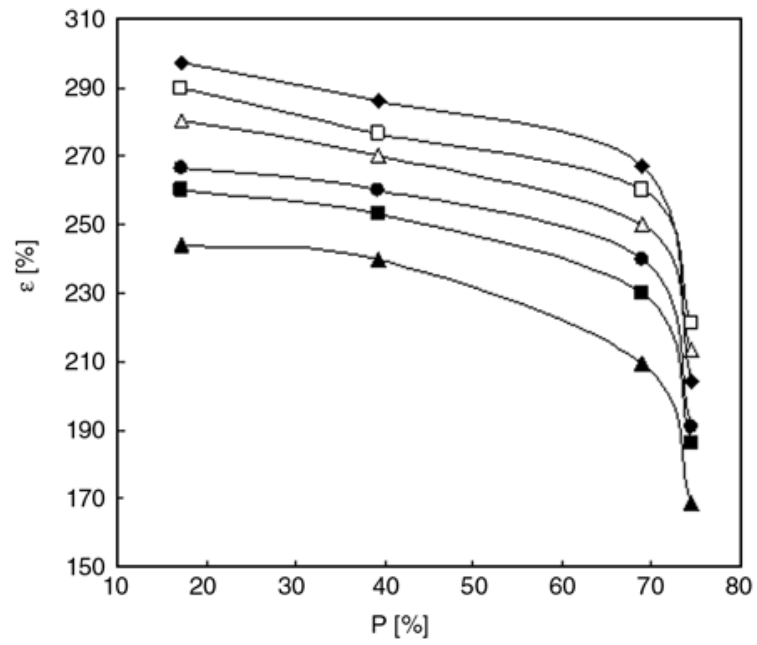

Figure 6. Dependence of the elongation $(\varepsilon[\%])$ of LDPEgraft-P4VP films $(\bullet)$ and their metal complexes with $\mathrm{Co}^{2+}(\square), \mathrm{WO}_{2}^{2+}(\Delta), \mathrm{MoO}_{2}^{2+}(\bullet), \mathrm{Fe}^{3+}(\mathbf{\bullet})$ and $\mathrm{VO}^{2+}(\mathbf{\Delta})$ on the degree of grafting of $4 \mathrm{VP}$ $(P[\%])$

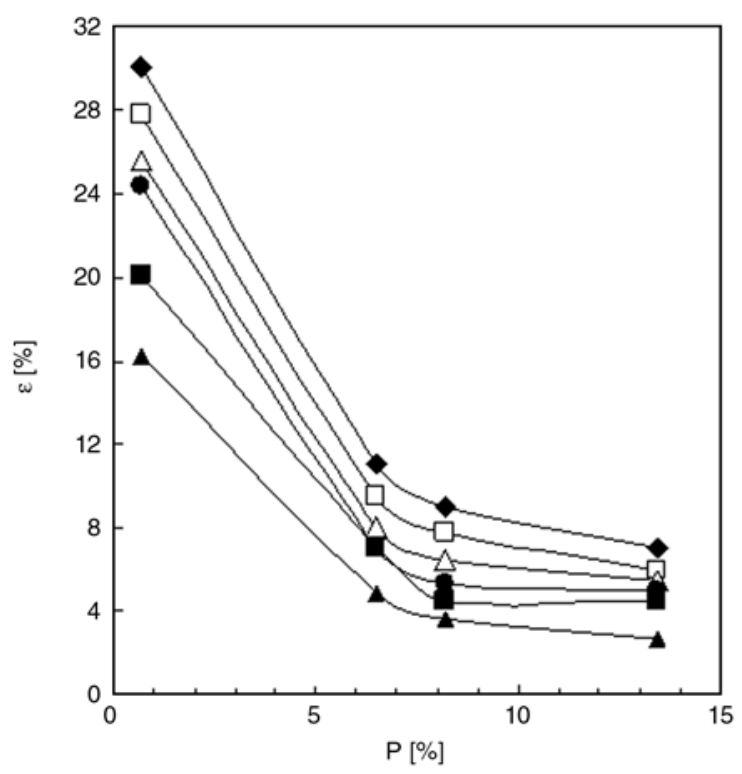

Figure 7. Dependence of the elongation ( $\varepsilon$ [\%]) of PTFEgraft-P4VP films $(\bullet)$ and their metal complexes with $\mathrm{Co}^{2+}(\square), \mathrm{WO}_{2}^{2+}(\Delta), \mathrm{MoO}_{2}^{2+}(\bullet), \mathrm{Fe}^{3+}(\bullet)$ and $\mathrm{VO}^{2+}(\mathbf{\Delta})$ on the degree of grafting of $4 \mathrm{VP}$ $(P[\%])$

mechanical strength in the following order: PTFEgraft -P4VP $<$ PTFE-graft-P4VP-Co ${ }^{2+}<$ PTFEgraft-P4VP-WO ${ }_{2}^{2+}<$ PTFE-graft-P4VP- $\mathrm{MoO}_{2}{ }^{2+} \leq$ PTFE-graft-P4VP-Fe ${ }^{3+}<$ PTFE-graft-P4VP$\mathrm{VO}^{2+}$.

For all the polymer complexes studied, the elongation decreased with the increase of the degree of grafting which can be explained with the formation of physical nodes of ion associates. Another proba- ble reason for the loss of elasticity could be related to the formation of cross-linked intra- and intermolecular structures involving the heavy metal ions present in the material. The elongation at break $(\varepsilon[\%])$ of all the metal complexes studied decreased with the increase of the degree of grafting. It changed from 290 to $170 \%$ for the complexes of LDPE-graft-P4VP and from 28 to $4 \%$ for the metal complexes of PTFE-graft-P4VP (remaining almost the same at degree of grafting 5\%) Figures 6 and 7.

\section{Conclusions}

Metal complexes of radiation-grafted nitrogen-containing copolymers were obtained using radiation grafted poly-4-vinylpyridine onto films of polyethene and polytetrafluoroethene by forming complexes with solutions of the following salts: $\mathrm{FeCl}_{3} \cdot 6 \mathrm{H}_{2} \mathrm{O}, \quad \mathrm{CoCl}_{2} \cdot 6 \mathrm{H}_{2} \mathrm{O}, \quad \mathrm{VOSO}_{4} \cdot 5 \mathrm{H}_{2} \mathrm{O}$, $\mathrm{Na}_{2} \mathrm{MoO}_{4} \cdot 2 \mathrm{H}_{2} \mathrm{O}$ and $\mathrm{Na}_{2} \mathrm{WO}_{4} \cdot 2 \mathrm{H}_{2} \mathrm{O}$. The introduction of metal ions in the copolymers was found to be from 0.03 to $34.48 \mathrm{mg}$ metal $/ \mathrm{g}$ and depended on the ion nature and its content in the complex. The formation of complexes with metal ions improved the electrochemical properties of the films compared to the initial copolymers. The materials obtained had electric resistance ranging from $10^{8}$ to $10^{3} \Omega \cdot \mathrm{m}$. The mechanical strength was found to increase to $29 \mathrm{MPa}$ at grafting degree of $69.0 \%$ for the metal complexes of LDPE-graft-P4VP and to $27.5 \mathrm{MPa}$ at grafting degree $8.2 \%$ for metal complexes of PTFE-graft-P4VP. For all the polymer metal complexes studied, the increase of the amount of metal ions in the polymer matrix resulted in a decrease of the elongation at break.

\section{References}

[1] Kariduraganavar M. Y., Nagarale R. K., Kittur A. A., Kulkarni S. S.: Ion-exchange membranes: preparative methods for electrodialysis and fuel cell applications. Desalination, 197, 225-246 (2006).

[2] Nagarale R. K., Gohil G. S., Shahi V. K.: Recent developments on ion-exchange membranes and electro-membrane processes. Advances in Colloid and Interface Science, 119, 97-130 (2006).

[3] Nasef M. M., Hegazy E. A.: Preparation and applications of ion exchange membranes by radiationinduced graft copolymerization of polar monomers onto non-polar films. Progress in Polymer Science, 29, 499-561 (2004). 
[4] Godjevargova T., Dayal R., Turmanova S.: Gluconic acid production in bioreactor with immobilized glucose oxidase plus catalase on polymer membranes adjacent to anion-exchange membrane. Macromolecular Bioscience, 4, 950-956 (2004).

[5] Hegazy E. A., El-Gammal B., Khalil F. H., Mabrouk T. M.: Evaluation of anionic-and cationic-supported hydrogel membranes for sorption of Th(IV) ions from nitric acid medium. Journal of Applied Polymer Science, 102, 320-332 (2006).

[6] Stamenova R., Tsvetanov C., Vassilev K., Tanielyan S., Ivanov S.: Polymer-supported molybdenum and vanadium catalysts for epoxidation of alkenes by alkyl hydroperoxides. Journal of Applied Polymer Science, 42, 807-812 (1991).

[7] Cheng K. W., Chan W. K.: Morphology of rhenium complex-containing polystyrene-block-poly(4-vinylpyridine) and its use as self-assembly templates for nanoparticles. Langmuir, 21, 5247-5250 (2005).

[8] Xi X., Liu Y., Shi J., Cao S.: Palladium complex of poly(4-vinylpyridine-co-acrylic acid) for homogeneous hydrogenation of aromatic nitro compounds. Journal of Molecular Catalysis A: Chemical, 192, 1-7 (2003).

[9] Fernando H. L., Uzcátegu G. C., Ortega M. C., Rivas A. B., Yanez J. E., Alvarez J.; Pardey A. J., Longo C.: Hydroesterification and hydroformylation of 1-hexene catalyzed by rhodium complexes immobilized on poly(4-vinylpyridine). Catalysis Today, 107, 273-281 (2005).

[10] El-Sawy N. M., Ali Z. I.: Iron(III) complexed with radiation-grafted acrylic acid onto poly(tetrafluoroethylene-co-perfluorovinyl ether) films. Journal of Applied Polymer Science, 103, 4065-4071 (2007).

[11] El-Sawy N. M., Al Sagheer F.: Radiation-induced graft polymerization of acrylic acid onto poly(tetrafluoroethylene-perfluorovinyl ether) copolymer films: complexation with some transition metals and biological activity. European Polymer Journal, 37, 161-166 (2001).
[12] El-Sawy N. M.: Complexation of rhodium on radiation-grafted acrylic acid onto poly(tetrafluoroethylene-perfluorovinyl ether) copolymer films. Journal of Applied Polymer Science, 67, 1449-1455 (1998).

[13] Abdel-Ghaffar M., Hegazy E. A., Dessouki A. M., ElAssy N. B., El-Sawy N. M.: Radiation-induced graft polymerization of acrylic acid onto fluorinated polymers-II.Graft copolymer-metal complexes obtained by radiation grafting onto poly(tetrafluoroethyleneperfluorovinyl ether) copolymer. International Journal of Radiation Applications and Instrumentation, Part C: Radiation Physics and Chemistry, 38, 369-375 (1991).

[14] Turmanova S., Vassilev K., Boneva S.: Preparation, structure and properties of metal-copolymer complexes of poly-4-vinylpyridine radiation-grafted onto polymer films. Reactive and Functional Polymers, in press (2007).

[15] Kostov G. K., Turmanova S. C.: Radiation-initiated graft copolymerization of 4-vinylpyridine onto polyethylene and polytetrafluoroethylene films and anionexchange membranes therefrom. Journal of Applied Polymer Science, 64, 1469-1475 (1997).

[16] Turmanova S., Vassilev K., Atanassov A.: Synthesis and properties of metal complexes of radiation grafted carboxyl containing copolymers. Journal of Applied Polymer Science, 102, 1658-1665 (2006).

[17] Subrahmanyan V., Lakshminarayanaiah N.: A rapid method for the determination of electrical conductance of ion-exchange membranes. Journal of Physic Chemistry, 72, 4314-4315 (1968).

[18] Clark R., Brown D.: The chemistry of vanadium, niobium and tantalum. Pergamon Press, Elmsford (1973).

[19] Hegazy E. A., Dessouki A. M., El-Sawy N. M., Abd El-Ghaffar M. A.: Radiation-induced graft polymerization of acrylic acid onto fluorinated polymers-II. Graft copolymer-metal complexes obtained by radiation grafting onto poly(tetrafluoroethylene-ethylene) copolymer. Journal of Polymer Science, Part A: Polymer Chemistry, 31, 527-533 (1993). 